\title{
Isolation and Characterization of Novel Plant Growth-Promoting Bacteria from the Fronds of Duckweed
}

\author{
TOMOKI IWASHITA 1 , YASUHIRO TANAKA ${ }^{2 *}$, HIDEYUKI TAMAKI ${ }^{3}$, RYOSUKE NAKAI ${ }^{4}$, \\ YASUKO YONEDA ${ }^{3}$, AYAKA MAKINO ${ }^{4}$, TADASHI TOYAMA ${ }^{1}$, YOICHI KAMAGATA ${ }^{3}$, \\ MASAAKI MORIKAWA ${ }^{5}$, and KAZUHIRO MORI ${ }^{1}$ \\ ${ }^{1}$ Graduate School of Engineering, University of Yamanashi \\ 14-3-11 Takeda, Kofu, Yamanashi 400-8511, Japan \\ ${ }^{2}$ Graduate School of Life and Environmental Sciences, University of Yamanashi \\ 14-4-37 Takeda, Kofu, Yamanashi 400-8510, Japan \\ ${ }^{3}$ Bioproduction Research Institute, National Institute of Advanced Industrial Science \\ and Technology (AIST)/1-1-1 Higashi, Tsukuba, Ibaraki 305-8566, Japan \\ ${ }^{4}$ Bioproduction Research Institute, National Institute of Advanced Industrial Science \\ and Technology (AIST)/2-17-2-1, Tsukisamu-higashi, Toyohira-ku, Sapporo 062-8517, Japan \\ ${ }^{5}$ Division of Biosphere Science, Graduate School of Environmental Science, Hokkaido University \\ Kita-10 Nishi-5, Kita-ku, Sapporo 060-0810, Japan
}

\begin{abstract}
To obtain novel plant growth-promoting bacteria that inhabit duckweed fronds, 25 bacterial strains isolated from the fronds of three duckweed species were subjected to twolevel screening, whereupon strain SP-2-C10 was selected as the most effective plant growthpromoting bacterium for the common duckweed Lemna minor. As the first-ever plant growth-promoting bacterium isolated from duckweed fronds, strain SP-2-C10 was found to belong to the rarely reported and taxonomically novel genus Aquidulcibacter (Class: Alphaproteobacteria). In an aseptic medium, this strain increased the growth of $L$. minor by 3.6-fold that of the bacteria-free plant. It even increased the growth of $L$. minor by 2.1fold in a non-sterile secondary sewage effluent. Strain SP-2-C10 colonized the fronds and roots of $L$. minor at almost similar cell densities under sterile conditions. By contrast, under non-sterile conditions (sewage effluent), the strain colonized the fronds more strongly than it did the roots, which was likely due to its isolation source- the fronds. This result might be useful information for constructing a functional water purification and/or biomass production system using duckweeds, whose functions were enhanced by inoculating useful microbes such as PGPB.
\end{abstract}

Key Words: duckweed, frond, plant growth-promoting bacteria, Aquidulcibacter

\section{INTRODUCTION}

Lemnoideae, commonly known as duckweed, is a subfamily of floating aquatic plants that are generally made up of two parts: fronds (fusion of the leaf and stem) and roots. Since duckweed are fast growing and easy to collect, they have been used for the removal of nutrients (nitrogen and phosphorus) from wastewater $^{1-6)}$. Duckweed also possess the ability to stimulate the microbial degradation of harmful recalcitrant organic compounds (e.g., nitrophenols, bisphenols, and nonylphenols) in their rhizosphere ${ }^{7-9)}$. Additionally, because duckweed grown under optimal conditions contain a high ratio of starch (ranging from $40 \%$ to $65 \%$ ) and protein (ranging from $15 \%$ to $45 \%{ }^{10)-12)}$, they can potentially be used as

\footnotetext{
* Corresponding author:

E-mail: yasuhiro@yamanashi.ac.jp

Tel: +81-55-220-8833; Fax: +81-55-220-8666
} 
a biofuel (bioethanol and biogas) or feedstuff resource ${ }^{10), 13}$. The microbes associated with duckweed are a key factor for enhancing the water purification ability and biomass productivity of the plants. Indeed, previous studies have reported the isolation of pollutant-degrading microbes and plant growth-promoting bacteria (PGPB) from the rhizosphere of duckweed and demonstrated how their re-inoculation into the rhizosphere or whole plant bodies of the host duckweed leads to enhancements in pollution removal and plant biomass productivity ${ }^{8,9), 14,15)}$.

Acinetobacter calcoaceticus strain P23, which was the first plant growth-promoting bacterial strain isolated from the whole body of Lemna aoukikusa, almost doubled the biomass productivity of this duckweed species $^{14), 16)}$. To date, over 15 strains of PGPB belonging to the genera, such as Pseudomonas, Acinetobacter, Sphingomonas, Azospirillum, and Aeromonas have been isolated from duckweed roots or whole plant bodies ${ }^{14), 15), 17)}$. However, to the best of our knowledge, PGPB have never been isolated from the fronds of duckweeds. We have previously reported that the microbial communities in the fronds of three species within the subfamily Lemnoideae (viz., Spirodela polyrhiza, Lemna minor, and Lemna aequinoctialis) were distinct from those growing in the $\operatorname{roots}^{18)}$, suggesting that the plant part (i.e., fronds or roots) is an important factor to consider when screening for key PGPB that will enhance the functional abilities of duckweed. Moreover, the fronds and roots of duckweed harbor a wide variety of taxonomically novel bacteria (i.e., showing less than $97 \%$ of $16 \mathrm{~S}$ rRNA gene sequence similarity to known type species), including the rarely cultivated phyla Acidobacteria, Armatimonadetes, and Verrucomicrobia $^{18)}$. If some of these taxonomically novel and rarely cultivated bacteria are PGPB, they might possess novel plant growth-promoting factors. Therefore, in this study, we aimed to identify novel PGPB using a bacterial library of taxonomically novel strains that we had previously isolated from the fronds of $L$. minor, $L$. aequinoctialis, and S. polyrhiza ${ }^{18)}$.

\section{MATERIALS AND METHODS}

Plant materials The plant L. minor was cultured aseptically in plant cultivation pots (420 mL; 70-mm diameter; IWAKI, Tokyo, Japan) containing $200 \mathrm{~mL}$ of Hoagland medium $\left(36.1 \mathrm{mg} / \mathrm{L} \mathrm{KNO}_{3}, 293 \mathrm{mg} / \mathrm{L} \mathrm{K}_{2} \mathrm{SO}_{4}\right.$, $3.87 \mathrm{mg} / \mathrm{L} \mathrm{NaH}_{2} \mathrm{PO}_{4}, 103 \mathrm{mg} / \mathrm{L} \mathrm{MgSO}_{4} \cdot 7 \mathrm{H}_{2} \mathrm{O}$, $147 \mathrm{mg} / \mathrm{L} \mathrm{CaCl}{ }_{2} \cdot \mathrm{H}_{2} \mathrm{O}, 3.33 \mathrm{mg} / \mathrm{L} \mathrm{FeSO}_{4} \cdot 7 \mathrm{H}_{2} \mathrm{O}$, $0.95 \mathrm{mg} / \mathrm{L} \mathrm{H}_{3} \mathrm{BO}_{3}, 0.39 \mathrm{mg} / \mathrm{L} \quad \mathrm{MnCl}_{2} \cdot 4 \mathrm{H}_{2} \mathrm{O}$, $0.03 \mathrm{mg} / \mathrm{L} \mathrm{CuSO}_{4} \cdot 5 \mathrm{H}_{2} \mathrm{O}, 0.08 \mathrm{mg} / \mathrm{L} \mathrm{ZnSO}_{4} \cdot$ $7 \mathrm{H}_{2} \mathrm{O}$, and $0.254 \mathrm{mg} / \mathrm{L} \mathrm{H}_{2} \mathrm{MoO}_{4} \cdot 4 \mathrm{H}_{2} \mathrm{O} ; \mathrm{pH}$ 7.0). The pots were kept in a growth chamber at $25^{\circ} \mathrm{C}$ (16,000 lux; $16: 8 \mathrm{~h}$ light: dark cycle).

Taxonomically novel bacterial strains An in-house bacterial library was used to source for strains that could grow rapidly and easily on R2A agar. The library was composed of taxonomically novel bacterial strains obtained from the fronds of the three duckweed species (L. minor, L. aequinoctialis, and S. polyrhiza), including strains that had been isolated in our previous study ${ }^{18}$. Within this library, 25 strains were determined to be suitable for testing in this study (Table 1).

First screening for PGPB Each novel bacterial strain was cultured on an R2A plate at $25^{\circ} \mathrm{C}$ for 7 days, following which the cells were suspended in $40 \mathrm{~mL}$ of Hoagland medium (final $\mathrm{OD}_{660}=0.1$ ) in a plant culture tube $(150 \mathrm{~mL} ; 40-\mathrm{mm}$ diameter; IWAKI). Next, one aseptic L. minor plant, which is commonly used for plant growth promotion testing ${ }^{15)-17)}$, was placed in the tube for coculture with the bacterial strain. The tube was incubated in a growth chamber at $25^{\circ} \mathrm{C}$ (16,000 lux; 16:8 h light: dark cycle) for 14 days ( $n=1$ for each bacterial strain), after which the number of fronds was counted. As a negative control, an aseptic (bacteria-free) L. minor plant was also cultured in the same medium in the same growth chamber. The plant growth-promoting effect (PGPE) was evaluated as the ratio of the number of fronds on the co-cultured plant to that on the negative control plant. Strains showing a PGPE ratio of greater than 2.5 were passed the first screening.

Second screening for PGPB The strains that had passed the first screening test were subjected to a second more thorough screening of their plant growth-promoting abilities. In 
Table 1 Taxonomically novel bacterial strains isolated from the fronds of duckweed based on 16S rRNA gene sequences (as of January 2015)

\begin{tabular}{|c|c|c|c|c|c|c|}
\hline Strain & Closest species & Phylum (Class) & $\begin{array}{c}\text { Similarity } \\
(\%)\end{array}$ & $\begin{array}{c}\text { Compared length } \\
(\mathrm{bp})\end{array}$ & Isolation source & $\begin{array}{c}\text { Accession } \\
\text { number }\end{array}$ \\
\hline SP-L9* & Hyphomicrobium hollandicum & Proteobacteria (Alpha) & 92 & 780 & S. polyrhiza & LC586318 \\
\hline $\mathrm{SP}-\mathrm{L} 7 \mathrm{~A} 7 *$ & Hyphomicrobium nitrativorans & Proteobacteria (Alpha) & 92 & 748 & S. polyrhiza & LC586319 \\
\hline SP-L6 & Flavitalea gansuensis & Bacteroidetes & 94 & 742 & S. polyrhiza & LC586320 \\
\hline SP-L45D9* & Hyphomicrobium nitrativorans & Proteobacteria (Alpha) & 93 & 796 & S. polyrhiza & LC586321 \\
\hline SP-L38D2* & Paucimonas lemoignei & Proteobacteria (Beta) & 94 & 703 & S. polyrhiza & LC586322 \\
\hline SP-L18* & Hydromonas duriensis & Proteobacteria (Beta) & 94 & 813 & S. polyrhiza & LC586323 \\
\hline $\mathrm{SP}-\mathrm{L} 15 \mathrm{~B} 3^{*}$ & Hyphomicrobium nitrativorans & Proteobacteria (Alpha) & 92 & 784 & S. polyrhiza & LC586324 \\
\hline $\mathrm{SP}-2-\mathrm{C} 10^{*}$ & Phenylobacterium kunshanense & Proteobacteria (Alpha) & 90 & 761 & S. polyrhiza & LC594658 \\
\hline LM-L39G5* & Methylibium petroleiphilum & Proteobacteria (Beta) & 94 & 833 & L. minor & LC586325 \\
\hline LM-L37E5 & Opitutus terrae & Verrucomicrobia & 93 & 831 & L. minor & LC586326 \\
\hline LM-L29E4 & Opitutus terrae & Verrucomicrobia & 93 & 831 & L. minor & LC586327 \\
\hline $\mathrm{LM}-\mathrm{L} 2 *$ & Deinococcus radiotolerans & Deinococcus-Thermus & 93 & 780 & L. minor & LC586328 \\
\hline LM-L18B3* & Methylibium petroleiphilum & Proteobacteria (Beta) & 94 & 830 & L. minor & LC586329 \\
\hline LM-L49A7 & Methylovirgula ligni & Proteobacteria (Alpha) & 94 & 793 & L. minor & LC586330 \\
\hline LA-L44D6* & Hyphomicrobium nitrativorans & Proteobacteria (Alpha) & 92 & 748 & L. aequinoctialis & LC586331 \\
\hline LA-L33A $5^{*}$ & Hyphomicrobium nitrativorans & Proteobacteria (Alpha) & 92 & 784 & L. aequinoctialis & LC586332 \\
\hline LA-L30F $4^{*}$ & Hyphomicrobium nitrativorans & Proteobacteria (Alpha) & 93 & 796 & L. aequinoctialis & LC586333 \\
\hline $\mathrm{LA}-\mathrm{L} 26 \mathrm{~B} 4$ & Flavitalea gansuensis & Bacteroidetes & 95 & 838 & L. aequinoctialis & LC586334 \\
\hline LA-L24H3* & Hyphomicrobium nitrativorans & Proteobacteria (Alpha) & 92 & 796 & L. aequinoctialis & LC586335 \\
\hline LA-L19C $3 *$ & Methylibium petroleiphilum & Proteobacteria (Beta) & 94 & 833 & L. aequinoctialis & LC586336 \\
\hline LA-L10B2* & Hyphomicrobium nitrativorans & Proteobacteria (Alpha) & 92 & 748 & L. aequinoctialis & LC586337 \\
\hline $\mathrm{LA}-34 \mathrm{~B} 5^{*}$ & Hyphomicrobium nitrativorans & Proteobacteria (Alpha) & 92 & 748 & L. aequinoctialis & LC586338 \\
\hline $\mathrm{LA}-3-\mathrm{El}{ }^{*}$ & Phyllobacterium trifolii & Proteobacteria (Alpha) & 93 & 701 & L. aequinoctialis & LC594659 \\
\hline $\mathrm{LA}-3-\mathrm{Bl}^{*}$ & Phyllobacterium trifolii & Proteobacteria (Alpha) & 93 & 701 & L. aequinoctialis & LC594660 \\
\hline $\mathrm{LA}-3-\mathrm{B} 2 *$ & Phyllobacterium trifolii & Proteobacteria (Alpha) & 93 & 701 & L. aequinoctialis & LC594661 \\
\hline
\end{tabular}

*The closest species and similarity of the strains are changed now along with updating the 16S rRNA database.

this second screening level, the inoculation concentration of bacterial cells was $\mathrm{OD}_{660}=$ 0.05 , which was half of that used in the first screening, and the PGPE test was conducted in triplicate. Except for these differences, the co-cultivation conditions were the same as those for the first screening. The strains showing a PGPE ratio of greater than 2.0 were considered to have passed the second screening level. Additionally, A. calcoaceticus strain P23 was tested as a positive control. This strain, which was isolated from the whole body of $L$. aoukikusa, was reported as a plant growth-promoting bacterium for duckweed $^{14), 16)}$. From this second screening, strain SP-2-C10 was selected as the best plant growth-promoting bacterium.

Indole-3-acetic acid production The ability of strain SP-2-C10 to produce indole-3-acetic acid (IAA) was evaluated according to a previously described method ${ }^{19)}$, with some modifications. The bacterial cells were dispensed $\left(\mathrm{OD}_{660}=0.05\right)$ into each well of a 96 -well microplate containing $500 \mu \mathrm{L}$ of $\mathrm{R} 2 \mathrm{~A}$ medium supplemented with $0.5 \% \quad(\mathrm{w} / \mathrm{v})$ L-tryptophan, and the plate was then incubated for 2 days at $25^{\circ} \mathrm{C}$ with shaking (550 rpm). Thereafter, $500 \mu \mathrm{L}$ of the culture broth was centrifuged $\left(20^{\circ} \mathrm{C}, 1,000 \mathrm{rpm}, 5\right.$ $\min$ ), and $450 \mu \mathrm{L}$ of the resultant supernatant was mixed with $600 \mu \mathrm{L}$ of Salkowski reagent (made up of $98 \mathrm{~mL}$ of $35 \% \mathrm{HClO}_{4}$ and $2 \mathrm{~mL}$ of $0.5 \mathrm{M} \mathrm{FeCl}_{3}$ ) and the mixture was incubated for $30 \mathrm{~min}$ at $25^{\circ} \mathrm{C}$. The formation of a pink to red color would indicate that the bacterium produced IAA.

Siderophore production The ability of the strain to produce siderophores was determined using the chrome azurol S (CAS)agar plate assay $^{20}$. In brief, a SP-2-C10 
colony growing on R2A agar was streaked onto the CAS agar and the plate was then incubated for 7 days at $25^{\circ} \mathrm{C}$ in the dark. The formation of a yellow to orange halo around each resultant colony would indicate that the bacterium produced siderophores.

Phosphate-solubilizing activity The ability of the strain to solubilize phosphate was measured using Pikovskaya's agar plate test ${ }^{21}$. In brief, a SP-2-C10 colony growing on R2A agar was streaked onto Pikovskaya's agar and the plate was then incubated for 7 days at $25^{\circ} \mathrm{C}$. The formation of a clear zone around each resultant colony would indicate that the strain had solubilized the phosphate in the agar.

PGPE of strain SP-2-C10 at different cell inoculation concentrations The cell inoculating concentration at which strain SP-2-C10 shows effective PGPE was tested using concentrations of $\mathrm{OD}_{660}=0.01,0.03,0.1$, and 0.3 , with the PGPE test conducted in triplicate. All other conditions of co-cultivation were the same as those used for the first screening.

PGPE in the secondary sewage effluent Ten $L$. minor plants were added to $40 \mathrm{~mL}$ of Hoagland medium in a plant culture tube containing strain SP-2-C10 $\left(\mathrm{OD}_{660}=0.3\right)$, and co-culture was carried out for 3 days in the growth chamber described above. Strain P23 was co-cultured with the duckweed in a similar way as a positive control. After the cultivation period, one plant from the coculture was transferred to $40 \mathrm{~mL}$ of a secondary effluent sample in a $150-\mathrm{mL}$ tube. This sewage sample had been collected from a municipal wastewater treatment plant in Kofu city, Yamanashi, Japan. As a negative control, an aseptic L. minor plant was also cultured in the same secondary sewage effluent. After culturing the L. minor plant in the sewage sample for 14 days in the growth chamber, the PGPE was evaluated.

Test of strain SP-2-C10 colonization on the fronds and roots of duckweed Strain SP2 -C10 was inoculated $\left(\mathrm{OD}_{660}=0.1\right)$ into two plant culture tubes containing $40 \mathrm{~mL}$ of Hoagland medium. Then, 15 L. minor plants were placed in each tube (total 30 plants) and incubation of the co-cultures was carried out in the growth chamber at $25^{\circ} \mathrm{C}$. After 3 days of incubation, five of the inoculated plants were transferred to new plant culture tubes containing $40 \mathrm{~mL}$ of Hoagland medium or secondary sewage effluent (two tubes for each medium were prepared) and cultivated for 3 or 7 days in the growth chamber. Each of the five plants from the bacterial inoculation and co-cultivation steps were gently washed twice with $10 \mathrm{~mL}$ of Hoagland medium in a $15-\mathrm{mL}$ conical tube. After the washing steps, a sterilized scalpel was used to cut off the fronds and roots. Total DNA was then extracted from these plant parts using the Cica Geneus DNA Extraction Reagent (Kanto Chemical Co., Tokyo, Japan) and purified using a Zymo-Spin column I (Funakoshi, Tokyo, Japan). The purified DNA was then amplified with the SYBR Green-based real-time polymerase chain reaction (qPCR) using the primer sets SP2-C10 F1 (5'-AGCCCATACCGGCGTGTGAT$\left.3^{\prime}\right)$ and SP-2-C10 R1 (5'-TCGCCGTTTTGACG GGCTTC- $3^{\prime}$ ), which were designed to amplify a specific 156 -bp part of the RNA polymerase subunit beta $(r p o B)$ gene of strain SP-2-C10 (amplification efficiency based on the standard curve was 97\%). The thermal cycling conditions used were as follows: $95^{\circ} \mathrm{C}$ for $10 \mathrm{~s}$, followed by 35 cycles of $94^{\circ} \mathrm{C}$ for $15 \mathrm{~s}, 57^{\circ} \mathrm{C}$ for $30 \mathrm{~s}$, and $72^{\circ} \mathrm{C}$ for $20 \mathrm{~s}$. Ten-fold serial dilutions $\left(1.27 \times 10^{3}\right.$ to $1.27 \times 10^{7}$ copies $\left./ \mu \mathrm{L}\right)$ of amplicons targeting the $r p o B$ gene of SP2-C10 (388 bp) were used as standards and had been amplified with the universal primer sets rpoB 1675 (5'-TGYCCGATYGAAACACC KGARGG-3') and rpoB 2063 (5'-TGACGYTG CATGTTCGMNCCCAT-3'), using the same thermal cycling conditions described in previous studies ${ }^{22)}$,23). To estimate the surface areas of the fronds and roots, images of $L$. minor plant samples were taken through a stereomicroscope and analyzed using ImageJ software (https://imagej.nih.gov/ij/).

\section{RESULTS AND DISCUSSION}

First screening for PGPB Twenty-five taxonomically novel strains (Table 1) isolated from the fronds of three duckweed species $(L$. minor, L. aequinoctialis, and S. polyrhiza) were subjected to the first screening test for PGPB. Five strains (viz., LA-L26B4, SP2-C10, LA-L10B2, LA-L33A5, and LAL24H3) elevated the growth of L. minor by 
more than 2.5-fold that of the aseptic plant, with strain LA-L26B4 showing the highest PGPE (3.7-fold) (Fig. 1). These five strains were therefore selected for the second screening.

Among the 25 strains examined, only two strains (i.e., LM-L29E4 and LM-L37E5) showed an inhibitory effect on the growth of the plants (0.6- to 0.8-fold). These two strains were members of Verrucomicrobia, a rarely cultivated bacterial phylum. Although the members of Verrucomicrobia are known to be widely distributed in nature ${ }^{24)-27)}$ and abundant in the fronds and roots of duckweed ${ }^{18), 28}$, how they interact with the plants and whether they affect the health and growth of the plants remain unclear. Therefore, our results provide an insight into the relationship (positive, neutral, or negative effect for the growth of plants) between the Verrucomicrobia and duckweeds.

Second screening for PGPB The five strains selected through the first screening process were subjected to a more thorough second screening of their PGPEs. Among them, only strain SP-2-C10 met the criterion for passing this screening step; that is, a 2.0fold increase in PGPE, almost the same level as that of $A$. calcoaceticus strain P23 (Fig. 2). Although the high SD value of PGPE for strain SP-2-C10 was observed in the experiment, this strain showed the stable PGPEs with low SD values in the after described experiment (see below; Fig. 3).

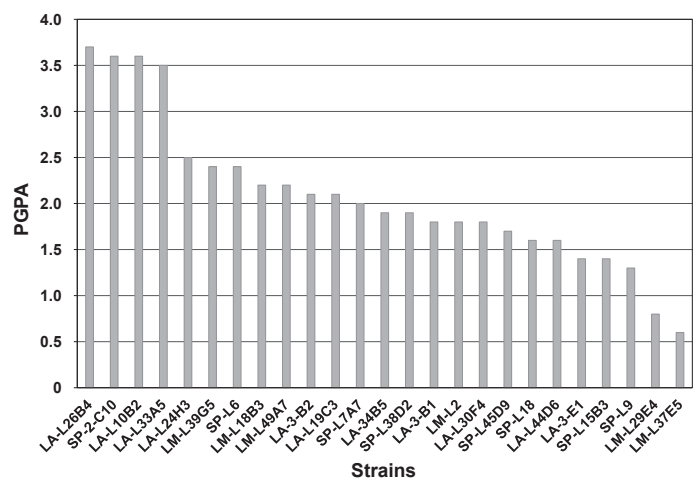

Fig. 1 Plant growth-promoting effect (PGPE) of 25 taxonomically novel bacterial strains isolated from the fronds of three species of duckweeds: Spirodela polyrhiza, Lemna minor, and Lemna aequinoctialis ( $n=1$ for each bacterial strain).
Therefore, strain SP-2-C10 was selected for further studies of its effectiveness in enhancing the functional activities of duckweed.

At the time of this experiment, strain SP-2C10 (belonging to the class Alphaproteobacteria) was determined to be a phylogenetically novel bacterium at the genus level based on its $16 \mathrm{~S}$ rRNA gene sequence similarity to other strains, where it showed a relatively low sequence similarity of $90 \%$ with its most closely related species, Phenylobacterium kunshanense. However, since that time, another bacterial strain has been isolated from cyanobacterial aggregates and proposed

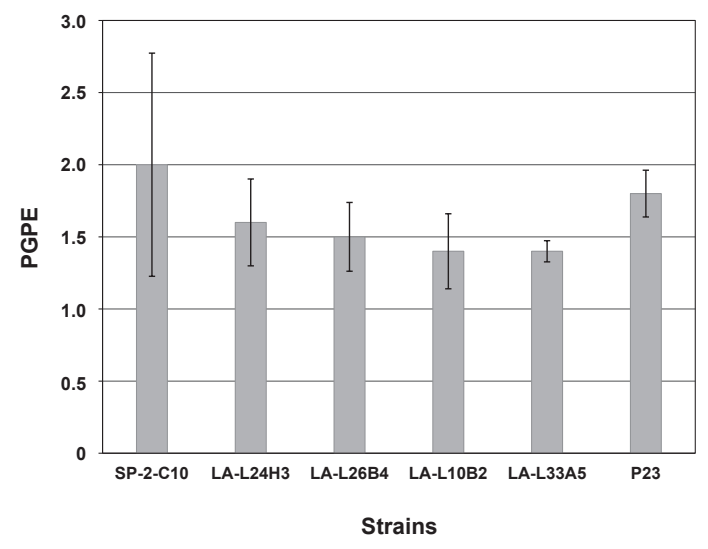

Fig. 2 Plant growth-promoting effect (PGPE) of five bacterial strains that passed the first screening and $A$. calcoaceticus strain P23 at the low bacterial concentration $(n=3)$. Error bars represent the standard deviation $( \pm S D)$.

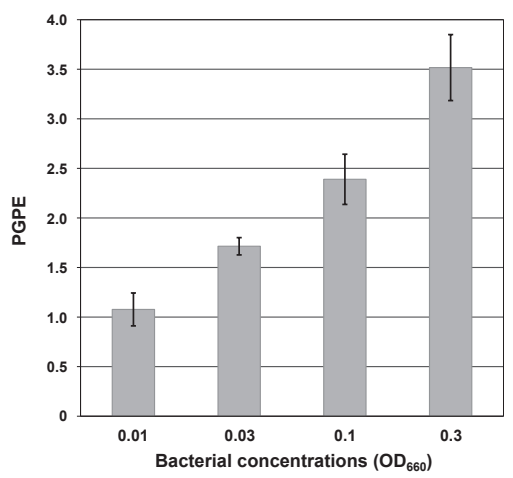

Fig. 3 Plant growth-promoting effect (PGPE) of strain SP-2-C10 inoculated at four different bacterial cell concentrations $(n=3)$. Error bars represent the standard deviation $( \pm S D)$. 
as a novel genus and species (Aquidulcibacter paucihalophilus strain $\left.\mathrm{TH} 1-2^{\mathrm{T}}\right)^{29)}$; the $16 \mathrm{~S}$ rRNA gene sequence of this species has $100 \%$ identity with that of strain SP-2-C10. To date, no other bacterial species or strains belonging to the new genus Aquidulcibacter have been isolated and there are no reports indicating its ecological roles though the organism perhaps may be associated with cyanobacteria to some extent. Therefore, the data obtained in this study would be useful for speculating the functions of this microbial group in nature, especially in aquatic environments. We speculate that at least some of the members of this genus might construct a beneficial relationship with duckweed in supporting plant growth.

Characterization of strain SP-2-C10 The plant growth-promoting factors (siderophore production, IAA production, and phosphate solubilization) of strain SP-2-C10 were examined. The strain showed positive siderophore production and phosphate solubilization activities, but no IAA production activity was detected (data not shown). Since duckweed can take up dissolved phosphate from the Hoagland medium or sewage effluent, phosphorus solubilization is unlikely to be involved in the bacterium's PGPE in these aquatic plants. Instead, siderophore production or other known (e.g., $\mathrm{NH}_{3}$ production, ACC deaminase production, and $\mathrm{N}_{2}$ fixation) or unknown plant growthpromoting factors might contribute to the PGPE of this strain.

Figure 3 shows the effects of different cell inoculation concentrations of SP-2-C10 on its PGPE in duckweed, where an $\mathrm{OD}_{660}$ value of 0.03 (equal to $3.9 \times 10^{8} \mathrm{CFU} / \mathrm{mL}$ ) or higher was shown to have the significant effects. The results suggest that an $\mathrm{OD}_{660}$ value of 0.03 could be the minimum threshold for obtaining effective PGPE from this strain.

PGPE in the secondary sewage effluent The PGPE of strain SP-2-C10 in a secondary sewage effluent that contained a wide variety of indigenous microbes was determined. As shown in Fig. 4, strain SP-2-C10 increased the frond number by 2.1-fold, and its average PGPE was almost equal to that of strain P23. Therefore, strain SP-2-C10 would definitely be able to realize the previously

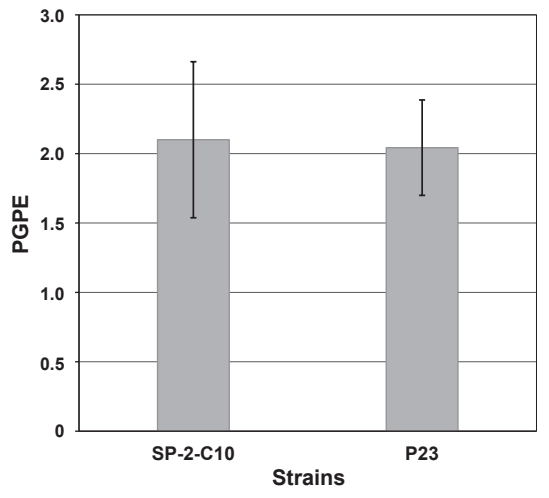

Fig. 4 Plant growth-promoting effect (PGPE) of strain SP-2-C10 and $A$. calcoaceticus strain P23 in secondary sewage effluent $(n=3)$. Error bars represent the standard deviation $( \pm S D)$.

conceptualized co-benefits of enhancing the water purification activity and biomass productivity of duckweed in wastewater systems $^{30)-32}$.

Ability of strain SP-2-C10 to colonize the fronds and roots of duckweed To evaluate the ability of strain SP-2-C10 to colonize duckweed fronds and roots, whole duckweed plants inoculated with the strain were cultured in sterile Hoagland medium or the non-sterile secondary sewage effluent, and the number of SP-2-C10 cells on the fronds and roots were measured by qPCR targeting of the $r p o B$ gene (The $r p o B$ gene of SP-2-C10 was not detected in DNA extracted from the secondary sewage effluent). In the sterile Hoagland medium, the number of SP-2-C10 cells on the fronds was almost the same as that on the roots throughout the experiment (Fig. 5A). By contrast, in the non-sterile secondary sewage effluent, the number of SP2 -C10 cells on the fronds was more than 10fold higher than that on the roots (Fig. 5B), most likely because the strain was originally isolated from the frond of duckweed. In wild duckweed with indigenous microbial communities, strain SP-2-C10 might mainly colonize the fronds rather than the roots. Taken together, our findings suggest that the isolation source (e.g., duckweed fronds or roots) may be a crucial factor to consider when searching for duckweed PGPB that will stably and sustainably enhance the plant biomass productivity both in practical field 

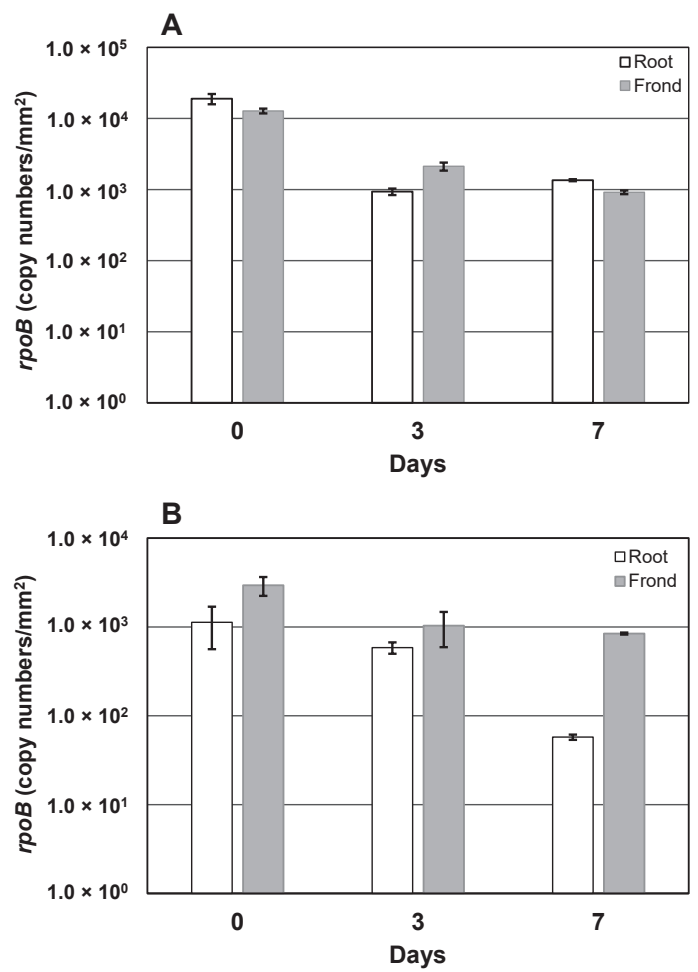

Fig. 5 Copy numbers of rpoB in strain SP-2-C10 on the fronds and roots of duckweed cultured in (A) sterile Hoagland medium and (B) secondary sewage effluent $(n=3)$. Error bars represent the standard deviation $( \pm S D)$.

conditions and in sterile laboratory ones.

\section{CONCLUSIONS}

In this study, we succeeded in obtaining a plant growth-promoting bacterial strain (SP2-C10) for duckweed. This strain is the firstever plant growth-promoting bacterium to be isolated from the fronds of duckweed and belongs to a rarely reported bacterial genus, Aquidulcibacter. Under the non-sterile conditions, strain SP-2-C10 increased the growth of L. minor by 2.1-fold and showed stronger colonization of the fronds than of the roots. These data suggest that the fronds are the most suitable habitat for this strain and that the isolation source (e.g., duckweed fronds or roots) would be an important factor to consider in the selection of PGPB for enhancing the co-benefit water purification and biomass production system using duckweeds.

\section{ACKNOWLEDGEMENTS}

We are grateful to Yamanashi Prefectural Wood Park at Kanegawa and the Society for the Research of Pro-Natural Civil Engineering Method of Yamanashi 303 for their help with the cultivation of aquatic plants. This research was partly supported by the Advanced Low Carbon Technology Research and Development Program (ALCA) of the Japan Science and Technology Agency (JST) under the grant number JPMJAL1108, and by the Cross-Ministerial Strategic Innovation Promotion Program (SIP), "Technologies for Smart Bio-industry and Agriculture", of the Cabinet Office, Government of Japan.

\section{REFERENCES}

1) Culley, D. D., Epps, E. A.: Use of duckweed for waste treatment and animal feed. $J$. WPCF., 45(2), 337-347 (1973)

2) Oron, G., Porath, D., Jansen, H.: Performance of the duckweed species Lemna gibba on municipal wastewater for effluent renovation and protein production. Biotechnol. Bioeng., 29(2), 258-268 (1987)

3) Zirschky, J., Reed, S. C.: The use of duckweed for wastewater treatment. J. Water Pollut. Control Fed., 60(7), 1253-1258 (1988)

4) Alaerts, G. J., Mahbubar, R., Kelderman, P.: Performance analysis of a full-scale duckweed-covered sewage lagoon. Water Res., 30(4), 843-852 (1996)

5) Vermaat, J. E., Hanif, K. M.: Performance of common duckweed species (Lemnaceae) and the waterfern Azolla filiculoides on different types of waste water. Water Res., 32(9), 2569-2576 (1998)

6) Goopy, J. P., Murray, P. J.: A review on the role of duckweed in nutrient reclamation and as a source of animal feed. AsianAust. J. Anim. Sci., 16(2), 297-305 (2003)

7) Hoang, H., Yu, N., Toyama, T., Inoue, D., Sei, K., Ike, M.: Accelerated degradation of a variety of aromatic compounds by Spirodela polyrrhiza-bacterial associations and contribution of root exudates released from S. polyrrhiza. J. Environ. Sci., 22(4), 494-499 (2010)

8) Kristanti, R. A., Kanbe, M., Toyama, T., Tanaka, Y., Tang, Y., Wu, X., Mori, K.: 
Accelerated biodegradation of nitrophenols in the rhizosphere of Spirodela polyrrhiza. J. Environ. Sci., 24(5), 800-807 (2012)

9) Li, Y., Toyama, T., Furuya, T., Iwanaga, K., Tanaka, Y., Mori, K.: Sustainable Biodegradation of bisphenol A by Spirodela polyrhiza in association with Novosphingobium sp. FID3. Jpn. J. Water Treat. Biol., 12(1), 43-54 (2014)

10) Xu, J., Cui, W., Cheng, J.J., Stomp, AM.: Production of high-starch duckweed and its conversion to bioethanol. Biosyst. Eng., 110(2), 67-72 (2011)

11) Xu, J., Dolan, M. C., Medrano, G., Cramer, C. L., Weathers, P. J.: Green factory: Plants as bioproduction platforms for recombinant proteins. Biotechnol. Adv., 30(5), 11711184 (2012)

12) Zhao, Z., Shi, H., Liu, Y., Zhao, H., Su, H., Wang, M., Zhao, Y.: The influence of duckweed species diversity on biomass productivity and nutrient removal efficiency in swine wastewater. Bioresour. Technol., 167, 383-389 (2014)

13) Stomp, AM.: The duckweeds: A valuable plant for biomanufacturing. Biotechnol. Annu. Rev., 11, 69-99 (2005)

14) Yamaga, F., Washio, K., Morikawa, M.: Sustainable biodegradation of phenol by Acinetobacter calcoaceticus P23 isolated from the rhizosphere of duckweed Lemna aoukikusa. Environ. Sci. Technol., 44(16), 6470-6474 (2010)

15) Ishizawa, H., Kuroda, M., Morikawa, M., Ike, M.: Evaluation of environmental bacterial communities as a factor affecting the growth of duckweed Lemna minor. Biotechnol. Biofuels, 10, 62-71 (2017)

16) Suzuki, W., Sugawara, M., Miwa, K., Morikawa, M.: Plant growth-promoting bacterium Acinetobacter calcoaceticus P23 increases the chlorophyll content of the monocot Lemna minor (duckweed) and the dicot Lactuca sativa (lettuce). J. Biosci. Bioeng., 118(1), 41-44 (2014)

17) Yamakawa, Y., Jog, R., Morikawa, M.: Effects of co-inoculation of two different plant growth-promoting bacteria on duckweed. Plant Growth Regul., 86, 287296 (2018)

18) Iwashita, T., Tanaka, Y., Tamaki, H., Yoneda, Y., Makino, A., Tateno, Y., Li, Y., Toyama, T., Kamagata, Y., Mori, K.: Comparative analysis of microbial communities in fronds and roots of three duckweed species: Spirodela polyrhiza, Lemna minor, and Lemna aequinoctialis. Microbes Environ., 35(3) (2020)

19) Bric, J. M., Bostock, R. M., Silverstone, S. E.: Rapid in situ assay for indoleacetic acid production by bacteria immobilized on a nitrocellulose membrane. Appl. Environ. Microbiol., 57(2), 535-538 (1991)

20) Schwyn, B., Neilands, J. B.: Universal chemical assay for the detection and determination of siderophores. Anal. Biochem., 160(1), 47-56 (1987)

21） Kumar, A., Prasad, S., Singh, S. K.: Screening of free living rhizobacteria associated with wheat rhizosphere for plant growth promoting traits. Afr. J. Agric. Res., 9(13), 1094-1100 (2014)

22) Giacomazzi, S., Leroi, F., Joffraud, JJ.: Comparison of three methods of DNA extraction from cold-smoked salmon and impact of physical treatments. J. Appl. Microbiol., 98, 1230-1238 (2005)

23) Ghaju Shrestha, R., Tanaka, Yasuhiro., Malla, B., Tandukar, S., Bhandari, D., Inoue, D., Sei, K., Sherchand, J. B., Haramoto, E.: Development of a quantitative PCR assay for Arcobacter spp. and its application to environmental water samples. Microb. Environ., 33(3), 309-316 (2018)

24）Bergmann, G. T., Bates, S. T., Eilers, K. G., Lauber, C. L., Caporaso, J. G., Walters, W. A., Knight, R., Fierer, N.: The under-recognized dominance of Verrucomicrobia in soil bacterial communities. Soil Biol. Biochem., 43(7), 1450-1455 (2011)

25) Chan, C. S., Chan, KG., Tay, YL., Chua, YH., Goh, K. M.: Diversity of thermophiles in a Malaysian hot spring determined using 16S rRNA and shotgun metagenome sequencing. Front. Microbiol., 6, 177 (2015)

26) Fujio-Vejar, S., Vasquez, Y., Morales, P., Magne, F., Vera-Wolf, P., Ugalde, J. A., Navarrete, P., Gotteland, M.: The gut microbiota of healthy Chilean subjects reveals a high abundance of the phylum Verrucomicrobia. Front. Microbiol., 8, 1221 (2017)

27) Chiang, E., Schmidt, M. L., Berry, M. A., Biddanda, B. A., Burtner, A., Johengen, T. H., Palladino, Danna., Denef, V. J.: Verruco- 
microbia are prevalent in north-temperate freshwater lakes and display class-level preferences between lake habitats. PLoS One, 13 (2018)

28) Matsuzawa, H., Tanaka, Y., Tamaki, H., Kamagata, Y., Mori, K.: Culture-dependent and independent analyses of the microbial communities inhabiting the giant duckweed (Spirodela polyrrhiza) rhizoplane and isolation of a variety of rarely cultivated organisms within the phylum Verrucomicrobia. Microbes Environ., 25(4), 302-308 (2010)

29) Cai, H., Shi, Y., Wang, Y., Cui, H., Jiang, H.: Aquidulcibacter paucihalophilus gen. nov., sp. nov., a novel member of family Caulobacteraceae isolated from cyanobacterial aggregates in a eutrophic lake. Antonie van Leeuwenhoek., 110, 1169-1177 (2017)

30) Ge, X., Zhang, N., Phillips, G. C., Xu, J.:
Growing Lemna minor in agricultural wastewater and converting the duckweed biomass to ethanol. Bioresour. Technol., 124, 485-488 (2012)

31) Yu, C., Sun, C., Yu, L., Zhu, M., Xu, H., Zhao, J., Ma, Y., Zhou, G.: Comparative analysis of duckweed cultivation with sewage water and $\mathrm{SH}$ media for production of fuel ethanol. PLoS One, 9 (2014)

32) Chen, G., Fang, Y., Huang, J., Zhao, Y., Li, Q., Lai, F., Xu, Y., Tian, X., He, K., Jin, Y., Zhao, H.: Duckweed systems for eutrophic water puri fi cation through converting wastewater nutrients to high- starch biomass: comparative evaluation of three different genera (Spirodela polyrhiza, Lemna minor and Landoltia punctata) in monoculture or polyculture. RSC. Adv., 8, 17927-17937 (2018)

(Submitted 2020. 11. 2)

(Accepted 2020. 11. 27) 